\title{
Dopamine receptor subtype 2 and somatostatin receptor subtype 5 expression influences somatostatin analogs effects on human somatotroph pituitary adenomas in vitro
}

\author{
M C Zatelli, D Piccin , F Tagliati, A Bottoni, M R Ambrosio, A Margutti, M Scanarini', \\ M Bondanelli, M D Culler ${ }^{2}$ and E C degli Uberti
}

Section of Endocrinology, Department of Biomedical Sciences and Advanced Therapies; University of Ferrara, Via Savonarola 9, 44100 Ferrara, Italy

${ }^{1}$ Division of Neurosurgery, Hospital of Padova, 35100 Padova, Italy

${ }^{2}$ Biomeasure Incorporated/IPSEN, Milford, MA 01757-3650, USA

(Requests for offprints should be addressed to E C degli Uberti; Email: ti8@unife.it)

\begin{abstract}
Dopamine (DA) and somatostatin (SRIF) receptor agonists inhibit growth hormone (GH) secretion by pituitary adenomas. We investigated DA subtype 2 receptor (DR2) and SRIF receptor (sst) subtypes 2 and 5 expression in $25 \mathrm{GH}$-secreting pituitary adenomas and tested in primary culture the effects on GH and prolactin (PRL) secretion of sst agonists selectively interacting with sst2 (BIM-23120), sst5 (BIM-23206), and sst2 and sst5 (BIM-23244). All adenomas expressed sst2; eight adenomas expressed both sst5 and DR2, eight sst5 but not DR2, and eight DR2 but not sst5. One tissue lacked expression of DR2 and sst5. GH secretion was inhibited by BIM-23120 in all samples, while it was reduced by BIM-23206 only in adenomas not expressing DR2. BIM-23120's inhibitory effects correlated with sst2 and DR2 expression, whereas DR2 expression correlated inversely with BIM-23206 inhibitory effects on GH secretion. In seven mixed GH-/PRL-secreting pituitary adenomas, PRL secretion was inhibited in sst5-expressing tumors by BIM-23206, but not by BIM-23120. BIM-23244 reduced PRL secretion only in adenomas expressing sst2, sst5 and DR2. sst5 and DR2 expression correlated directly with BIM23206 inhibitory effects on PRL secretion. Our results suggest that adenomas expressing DR2 are less likely to respond to clinically available SRIF analogs in terms of GH secretion inhibition. Therefore, drugs interacting also with DR2 might better control secretion of pituitary adenomas.
\end{abstract}

Journal of Molecular Endocrinology (2005) 35, 333-341

\section{Introduction}

Somatostatin (SRIF) is known to inhibit growth hormone $(\mathrm{GH})$ secretion by normal and neoplastic somatotroph cells, both in vivo (Melmed et al. 1998) and in vitro (Shimon et al. 1997), interacting with five distinct receptors (sst1-sst5), expressed at various levels in pituitary tumors (Patel 1999). Recently, pituitary sst expression has been shown to correlate with the inhibitory effects of SRIF analogs on GH secretion in vitro (Jaquet et al. 2000, Zatelli et al. 2003, Hofland et al. 2004). Moreover, a complex interplay between the different ssts is suggested by the evidence that G-protein-coupled receptors (GPCRs) form homo- and heterodimers (Rocheville et al. 2000a), supporting a greater functional diversity. This scenario is further complicated by the demonstration of functional dimerization between dopamine (DA) receptor subtype 2 (DR2) and sst5 in vitro (Rocheville et al. 2000b). DA interacts with a family of five GPGRs (DR1-DR5), and DR2 seems to be the more predominant subtype in the anterior pituitary (Koga et al. 1987, Wood et al. 1991). DA agonists are the first choice for treatment of prolactin (PRL)-secreting pituitary adenomas and have been employed also in the treatment of GH-secreting pituitary adenomas, until SRIF analogs became available in clinical practice. Since DA attenuates GH secretion in acromegalic patients, DA agonists, including bromocriptine and cabergoline, have been used as either primary or adjuvant therapy for acromegaly (Vance et al. 1984) and cabergoline has been reported to suppress $\mathrm{GH}$ to less than $2 \mu \mathrm{g} / \mathrm{l}$ and to normalize insulin-like growth factor I in up to $30 \%$ of patients with acromegaly (Abs et al. 1998). DA agonists are preferred in acromegalic patients with coexistent hyperprolactinemia (Melmed et al. 2002), having an improved therapeutic efficacy when combined with SRIF analogs (Jaffe and Barkan 1992). Moreover, recent studies have shown that a chimeric molecule, interacting with both sst2 and DR2, has an enhanced potency in suppressing GH and PRL secretion from pituitary adenomas, suggesting an interaction between the two receptors 
Table 1 Clinical data for acromegalic patients and in vitro $\mathrm{GH}$ and $\mathrm{PRL}$ secretion in pituitary adenomas

\begin{tabular}{|c|c|c|c|c|c|c|c|c|}
\hline \multirow[b]{2}{*}{ No. } & \multirow[b]{2}{*}{ Sex } & \multirow[b]{2}{*}{ Age } & \multirow{2}{*}{$\begin{array}{l}\text { Immuno- } \\
\text { histochemistry }\end{array}$} & \multicolumn{3}{|c|}{ In vivo $(\mu \mathrm{g} / \mathrm{l})$} & \multicolumn{2}{|c|}{ In vitro ${ }^{a}(\mu \mathrm{g} / \mathrm{l})$} \\
\hline & & & & $\mathrm{GH}$ & IGF-I & PRL & $\mathrm{GH}$ & PRL \\
\hline \multicolumn{9}{|c|}{ [sst2+, sst5+, DR2+] adenomas } \\
\hline $1 \mathrm{~V}$ & $\mathrm{~F}$ & 32 & $\mathrm{GH}$ & 101 & 1397 & $32 \cdot 5$ & $67 \cdot 2$ & - \\
\hline 2 & M & 42 & $\mathrm{GH}, \mathrm{PRL}$ & 100 & 870 & $3 \cdot 3$ & $12 \cdot 8$ & - \\
\hline 3 & $\mathrm{~F}$ & 42 & $\mathrm{GH}$ & 24.5 & 367.9 & $21 \cdot 3$ & $137 \cdot 2$ & - \\
\hline 4 & $\mathrm{~F}$ & 47 & $\mathrm{GH}, \mathrm{PRL}$ & $46 \cdot 7$ & 876 & 14 & $24 \cdot 7$ & - \\
\hline 5 & $\mathrm{~F}$ & 38 & $\mathrm{GH}$ & 16 & 808 & $14 \cdot 2$ & $15 \cdot 1$ & - \\
\hline 6 & M & 35 & $\mathrm{GH}, \mathrm{PRL}$ & $19 \cdot 5$ & $928 \cdot 7$ & $10 \cdot 4$ & 111.5 & - \\
\hline 7 & $\mathrm{~F}$ & 57 & $\mathrm{GH}, \mathrm{PRL}$ & 29 & 1000 & $48 \cdot 7$ & $40 \cdot 1$ & $6 \cdot 9$ \\
\hline 8 & $\mathrm{~F}$ & 25 & $\mathrm{GH}, \mathrm{PRL}$ & $36 \cdot 6$ & 729 & $62 \cdot 3$ & 133.9 & $109 \cdot 8$ \\
\hline \multicolumn{9}{|c|}{ [sst2+, sst5+, DR2-] adenomas } \\
\hline 9 & $\mathrm{~F}$ & 23 & $\mathrm{GH}, \mathrm{PRL}$ & 20 & 1000 & $46 \cdot 9$ & $47 \cdot 2$ & $6 \cdot 8$ \\
\hline 10 & M & 40 & $\mathrm{GH}$ & 10 & 1000 & $9 \cdot 2$ & $74 \cdot 8$ & - \\
\hline 11 & $M$ & 56 & $\mathrm{GH}$ & 3 & 287 & $9 \cdot 8$ & 5.4 & - \\
\hline 12 & M & 42 & $\mathrm{GH}$ & $2 \cdot 4$ & 341 & $8 \cdot 3$ & $8 \cdot 9$ & - \\
\hline 13 & M & 32 & $\mathrm{GH}$ & $20 \cdot 8$ & 528 & $12 \cdot 7$ & $3 \cdot 2$ & - \\
\hline 14 & $\mathrm{~F}$ & 42 & $\mathrm{GH}$ & 63 & 583 & $15 \cdot 8$ & $3 \cdot 7$ & - \\
\hline 15 & $\mathrm{~F}$ & 35 & $\mathrm{GH}, \mathrm{PRL}$ & 19 & 650 & $56 \cdot 7$ & 173 & 4.4 \\
\hline 16 & $\mathrm{~F}$ & 81 & $\mathrm{GH}$ & $34 \cdot 2$ & $792 \cdot 3$ & $22 \cdot 8$ & $7 \cdot 4$ & - \\
\hline \multicolumn{9}{|c|}{ [sst2+, sst5-, DR2+] adenomas } \\
\hline 17 & M & 56 & $\mathrm{GH}$ & $9 \cdot 6$ & 439 & 6 & $89 \cdot 7$ & - \\
\hline 18 & $\mathrm{~F}$ & 49 & $\mathrm{GH}, \mathrm{PRL}$ & $2 \cdot 4$ & 630 & 62 & $115 \cdot 9$ & $6 \cdot 1$ \\
\hline 19 & $\mathrm{~F}$ & 56 & $\mathrm{GH}, \mathrm{PRL}$ & 8.9 & 615 & 45 & $77 \cdot 3$ & $6 \cdot 8$ \\
\hline 20 & M & 53 & $\mathrm{GH}$ & $11 \cdot 3$ & 601 & 0.4 & 135 & - \\
\hline 21 & M & 21 & $\mathrm{GH}, \mathrm{PRL}$ & 6.92 & 766 & 40 & 238 & 44 \\
\hline 22 & $\mathrm{~F}$ & 44 & $\mathrm{GH}$ & $9 \cdot 1$ & 645 & 13 & $76 \cdot 7$ & - \\
\hline 23 & $\mathrm{~F}$ & 30 & $\mathrm{GH}$ & $14 \cdot 4$ & 901 & 1.75 & $96 \cdot 6$ & - \\
\hline 24 & M & 57 & $\mathrm{GH}$ & $9 \cdot 6$ & 439 & 9 & 207 & - \\
\hline \multicolumn{9}{|c|}{ [sst2+, sst5-, DR2-] adenoma } \\
\hline 25 & $\mathrm{~F}$ & 26 & $\mathrm{GH}, \mathrm{PRL}$ & 26 & 950 & $62 \cdot 5$ & $157 \cdot 9$ & $7 \cdot 2$ \\
\hline
\end{tabular}

${ }^{a} \mathrm{GH}$ and PRL levels $(\mu \mathrm{g} / \mathrm{l})$ in control culture medium from $12 \times 10^{4}$ cells cultured for $12 \mathrm{~h}$. IGF-I. insulin-like growth factor 1 .

(Saveanu et al. 2002, Ren et al. 2003). However, it is unknown whether DR2 expression influences the effects of SRIF analogs on pituitary tumors.

We therefore investigated sst2, sst5 and DR2 expression pattern in somatotroph adenomas and tested in primary culture their response to SRIF-selective analogs interacting with sst2 and/or sst5, in terms of GH and PRL secretion inhibition.

\section{Materials and methods}

\section{Human pituitary adenomas}

25 patients, 10 males and 15 females, aged $42 \cdot 4 \pm 3 \cdot 3$ y (median, $42 \mathrm{y}$; range, 23-81 y) were diagnosed with acromegaly on the basis of clinical presentation, with pre-operative elevated serum GH $(25 \cdot 2 \pm 5 \cdot 5 \mu \mathrm{g} / \mathrm{l}$, not declining to less than $1 \mu \mathrm{g} / \mathrm{l}$ during an oral glucose tolerance test) and insulin-like growth factor I levels $(725 \cdot 8 \pm 52 \cdot 6 \mu \mathrm{g} / \mathrm{l})$ as expected for the age group, and sellar magnetic resonance imaging consistent with a pituitary macroadenoma (mean maximal diameter, $2 \cdot 07 \pm 0.8 \mathrm{~cm}$; mean volume, $\left.3.5 \pm 0.7 \mathrm{~cm}^{3}\right)$. Serum PRL was normal in 17 patients $(12 \pm 1.6 \mu \mathrm{g} / \mathrm{l})$ and elevated to $>30 \mu \mathrm{g} / \mathrm{l}$ in eight $(53 \pm 1 \cdot 8 \mu \mathrm{g} / \mathrm{l})$. Table 1 shows patients' characteristics and pre-operative hormonal values. All patients underwent trans-sphenoidal surgery, with sparing of the normal pituitary, and immunohistochemical examination for anterior pituitary hormones showed staining for $\mathrm{GH}$ in all cases, and also for PRL in 11 cases. Informed consent of the patients was obtained for disclosing clinical investigation and performing the in vitro study.

\section{Tissue collection and primary culture}

The collection and use of tumor samples were in accordance with the guidelines of the local committee on human research. Tissue samples were collected under sterile conditions at the time of surgery, and a fragment 
was immediately frozen in liquid nitrogen and stored at $-80{ }^{\circ} \mathrm{C}$ until RNA isolation was performed. A portion of the fresh tissue was processed for primary culture, as described previously (Zatelli et al. 2003). Cells were resuspended in low-glucose Dulbecco's modified Eagle's medium with $10 \%$ fetal bovine serum and antibiotics (EuroClone, Wetherby, UK), seeded in 96-well culture plates and incubated at $37^{\circ} \mathrm{C}$ in a humidified atmosphere of $5 \% \mathrm{CO}_{2} / 95 \%$ air. Medium was then changed to serum-free low-glucose Dulbecco's modified Eagle's medium containing $0 \cdot 2 \%$ BSA, $120 \mathrm{nM}$ transferrin, 5 $\mathrm{U} / \mathrm{l}$ insulin, $2 \mathrm{mM}$ glutamine and antibiotics, and cells were treated for $6 \mathrm{~h}$ with $10^{-8} \mathrm{M}$ SRIF analogs. Medium was then collected and stored at $-20{ }^{\circ} \mathrm{C}$ for later hormone measurement. Fibroblast contamination was excluded by examining the morphology of cultured cells (Danila et al. 2001).

\section{Isolation of RNA and reverse transcription (RT)-PCR}

In order to demonstrate the pituitary origin of the samples, RT-PCR analysis for GH expression was performed in each specimen, and further expression analysis for sst2, sst5 and DR2 was performed only in GHexpressing tissues. Total RNA from the tumors was extracted with TRIzol reagent (Invitrogen, Milano, Italy) according to the manufacturer's protocol, and processed for RT-PCR analysis, as described previously (Zatelli et al. 2001). PGR conditions and oligonucleotide primers for amplification of GH, sst2 and sst5 were described previously (Zatelli et al. 2003). Amplification of DR2 cDNA (201 bp) was obtained by using the following primers and PCR conditions for 35 cycles: forward, 5'-CGCTT CATTGTCACGCTGCT-3'; reverse, 5'-CGTGTTCA CTGGGAAACTCCC-3'. PCR conditions were as follows: denaturation at $95{ }^{\circ} \mathrm{C}$ for $20 \mathrm{~s}$, annealing at $55^{\circ} \mathrm{C}$ for $20 \mathrm{~s}$ and extension at $72{ }^{\circ} \mathrm{C}$ for $30 \mathrm{~s}$. PCR products were run on a $2 \%$ agarose gel, visualized by ethidium bromide staining and analyzed with the Fluor-S Multi Imager (Bio-Rad, Milano, Italy). To confirm the correct identification of RT-PCR products, their specificity was verified, after gel-purification by Quiaex II (Qiagen, Valencia, CA, USA), by restriction-enzyme digestion and direct sequencing (data not shown).

\section{Quantitative PCR for sst2, sst5 and DR2 mRNAs}

Quantitative PGR for sst2 and sst5 was performed as described previously (Zatelli et al. 2003, 2005), with primers and probes designed using Primer Express Software (Applied Biosystems, Monza, Italy). TaqMan probes (PE Applied Biosystems) labelled with a fluorescent dye (6-carboxy-fluorescein; FAM) and a quencher dye (6-carboxy-tetramethyl rhodamine; TAMRA) were used. For amplification of the housekeeping gene the Pre-Developed TaqMan Assay
Table 2 Human sst subtype specificity $\left(\mathrm{IC}_{50} \cdot(\mathrm{nM})\right)$

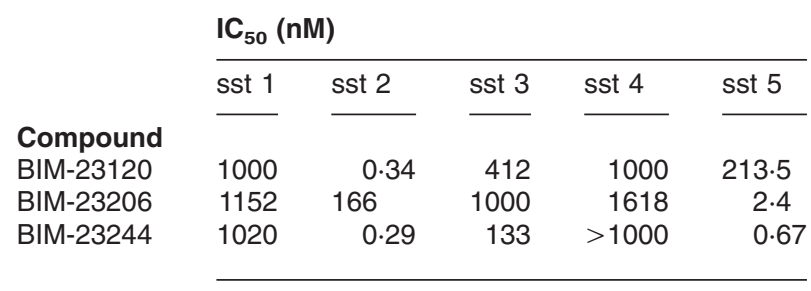

Reagents for the Human 18 S rRNA $(20 \times)$ were used (PE Applied Biosystems).

Concerning DR2 amplification, Assay on Demand Hs00241436_ml (Applied Biosystems) was used. Absolute quantitation of mRNA copy number in the samples was carried out following the Standard Curve Methods (Separate Tubes; User Bulletin no. 2 ABI PRISM 7700 Sequence Detection System; PE Applied Biosystems). Serial dilutions of the single-stranded sst2, sst5 and DR2 sense oligonucleotide amplicons (from $10^{9}$ to $10^{2}$ molecules) were carried out in triplicate. The log copy numbers of unknown samples were calculated from the regression line according to the equation: $\log$ $\mathcal{N}=(C t-q) / m$, where $C t$ is the threshold cycle, $q$ is the $y$ intercept and $m$ is the slope of the standard curve line. All quantitative PCRs were performed, recorded and analyzed using the ABI 7700 Prism Sequence Detection System. Slopes for all assays reported were $-3 \cdot 3 \pm 0 \cdot 1$.

All samples were carried out in triplicate $(100 \mathrm{ng}$ of reverse-transcribed total RNA per well) and repeated at least twice. For each sample one point of $18 \mathrm{~S}$ rRNA was loaded to evaluate the retro-transcription efficiency in the same plate and PCR conditions. A no-template control and RT controls were run in each experiment.

A cut-off of $3 \times 10^{3}$ mRNA copies/ $\mu \mathrm{g}$ total RNA was established as the threshold for real-time PGR to exclude the detection of transcripts due to illegitimate transcription, as suggested previously (Chelly et al. 1989, Korbonits et al. 2001).

\section{sst-selective agonists}

sst-selective agonists used in this study (BIM-23120, BIM-23206, BIM-23244) were provided by Biomeasure Incorporated/IPSEN (Milford, MA, USA) and their respective affinities to the different ssts are listed in Table 2. Specificity and selectivity of the analogs were determined by radioligand binding assay (Shimon et al. 1997, Saveanu et al. 2001), and biological activity of sst-selective agonists was evaluated as described by Shimon et al. (1997).

\section{Hormone assay}

To explore the effects of sst-selective agonists on pituitary primary cultures, human GH and PRL levels 
were measured by immunoradiometric assay (IRMA) with reagents supplied by the Nichols Institute Diagnostics (San Juan Capistrano, CA, USA). The limit of detection for $\mathrm{GH}$ was $0.05 \mu \mathrm{g} / \mathrm{l}$, with intra- and interassay variation coefficients of $3 \cdot 3$ and $6 \cdot 1 \%$, respectively. The limit of detection for PRL was $0.47 \mu \mathrm{g} / \mathrm{l}$, with intra- and interassay variation coefficients of $6 \cdot 4$ and $5 \cdot 9 \%$, respectively. Hormone assays were performed in duplicate after appropriate sample dilutions of medium from cells treated for $6 \mathrm{~h}$ with each compound at $10^{-8} \mathrm{M}$ (conditioned medium) in eight replicates for each pituitary adenoma.

\section{Statistical analysis}

Results are expressed as means \pm S.E Student's paired or unpaired $t$-test was used to evaluate individual differences between means. To measure the strength of association between pairs of variables without specifying dependencies, Spearman order correlations were run. A $P<0 \cdot 05$ was considered significant in all tests.

\section{Results}

\section{SRIF and DA receptor mRNA expression}

All tissue samples expressed $\mathrm{GH}$, confirming their pituitary origin, and therefore each RNA was subjected to RT-PCR to investigate the expression of sst2, sst5 and DR2. We found that sst2 was expressed in all adenomas, sst5 in 16 and DR2 in 16. On the basis of sst and DR expression, four patterns were identified among the 25 tissues: eight adenomas expressed sst2, sst5 and DR2 ([sst2+, sst5+, DR2+] adenomas), eight expressed sst2 and sst5, but not DR2 ([sst2+, sst5+, DR2 - ] adenomas) and eight expressed sst2 and DR2, but not sst5 ([sst2+, sst5 -, DR2+] adenomas). Only one adenoma lacked expression of both sst5 and DR2 ([sst2+, sst5 - , DR2 - ] adenoma).

sst and DR expression were verified further by quantitative PGR (see Table 3). sst2 was expressed at almost the same mRNA level in [sst2+, sst5+, DR2+], $[\mathrm{sst} 2+, \mathrm{sst} 5+, \mathrm{DR} 2-]$ and [sst2+, sst5 -, DR2+] adenomas $\left((6 \cdot 7 \pm 1 \cdot 3) \times 10^{7}\right.$ molecules $/ \mu \mathrm{g}$ reverse transcribed total RNA). Sample 25 (lacking expression of both sst5 and DR2) expressed higher sst2 mRNA levels $\left(24 \times 10^{7}\right.$ molecules $/ \mu \mathrm{g}$ of reverse-transcribed total RNA). Moreover, real-time PGR confirmed the lack of sst5 expression in [sst2+, sst5 -, DR2+] adenomas and in adenoma 25, and the lack of DR expression in [sst2+, sst5+, DR2 - ] adenomas and in adenoma $25\left(<3 \times 10^{3}\right.$ mRNA copies $/ \mu \mathrm{g}$ reverse-transcribed total RNA). sst5 expression was $>3$ fold higher in [sst2+, sst5+, DR2+] than in $[\mathrm{sst} 2+$, sst5,$+ \mathrm{DR} 2-]$ adenomas $((1 \cdot 1 \pm 0 \cdot 2) \times$ $10^{5}$ compared with $(3 \cdot 6 \pm 0 \cdot 7) \times 10^{4}$ molecules $/ \mu \mathrm{g}$ reverse-transcribed total RNA; $P<0 \cdot 01)$. DR2 expression was $>30$-fold higher in $[$ sst2 + , sst5,$+ \mathrm{DR} 2+]$ than in $\left[\right.$ sst2+, sst5,$- \quad$ DR2+] adenomas $\left((7 \cdot 8 \pm 1 \cdot 6) \times 10^{5}\right.$ compared with $(2 \cdot 4 \pm 0 \cdot 6) \times 10^{4}$ molecules $/ \mu \mathrm{g}$ reversetranscribed total RNA; $P<0 \cdot 01)$.

\section{Effects of selective SRIF analogs on GH secretion}

All 25 pituitary primary cultures secreted measurable amounts of GH in the culture medium (see Table 1). Therefore, to investigate whether DR2 expression influences the effects of SRIF analogs on GH secretion in vitro, GH levels were measured in conditioned media from adenomas treated for $6 \mathrm{~h}$ with or without $10^{-8} \mathrm{M}$ sst-selective agonists.

As shown in Fig. 1A and Table 3, we found that in $[\mathrm{sst} 2+$, sst5+, DR2+] adenomas treatment with the sst2-selective agonist (BIM-23120), with the combination of the sst2-selective agonist and the sst5-selective agonist (BIM-23120+BIM-23206) or with the sst2/sst5 dual agonist (BIM-23244) significantly inhibited GH secretion on average by $15-24 \%(P<0 \cdot 05)$, whereas treatment with the sst5-selective agonist (BIM-23206) did not modify the secretory activity of pituitary cells in vitro and did not potentiate the inhibitory effects of BIM-23120.

As shown in Fig. 1B and Table 3, in [sst2+, sst5+, DR2 - ] adenomas GH secretion was significantly reduced by treatment with BIM-23120 or BIM-23206 $(P<0 \cdot 05)$, and even more so by treatment with BIM-23120+BIM-23206, or with BIM-23244 $(P<0 \cdot 01$; on average, $18-57 \%)$. An additive effect was indeed observed after co-treatment with the sst2- and sst5-selective agonists and after treatment with the dual sst2/sst5 agonist, which had a greater inhibitory effect on GH secretion as compared with treatment with BIM-23120 or with BIM-23206 alone $(P<0 \cdot 05)$. Treatment with BIM23206, with BIM-23206+BIM23120 or with BIM-23244 were more effective in reducing GH secretion in [sst2+, sst5+, DR2-] adenomas as compared with [sst2+, sst5+, DR2+] adenomas $(P<0 \cdot 05)$.

As shown in Fig. 1C and Table 3, in the eight [sst2+, sst5 -, DR2+] adenomas GH secretion was significantly $(P<0.05)$ inhibited by BIM-23120, BIM23120+BIM-23206 and BIM-23244 on average by 18-30\%, while BIM-23206 alone had no effect. Treatment with each sst analog did not modify GH secretion by adenoma 25, which lacked expression of both sst5 and DR2.

Moreover, sst2 expression correlated directly with the inhibitory effects of BIM-23120 $\left(r^{2}=0 \cdot 73, P<0 \cdot 01\right)$ on GH secretion, whereas sst5 expression did not correlate with the inhibitory effects of BIM-23206. DR2 expression directly correlated with the inhibitory effects of BIM-23120 $\left(r^{2}=0.51, \quad P<0 \cdot 05\right)$, but correlated inversely with inhibitory effects of BIM-23206 $\left(r^{2}=0.52\right.$, $P<0 \cdot 05)$. 


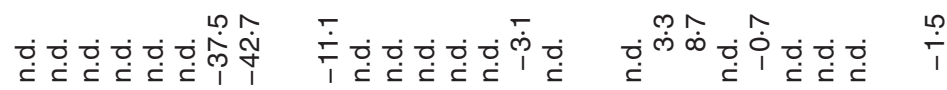

옹

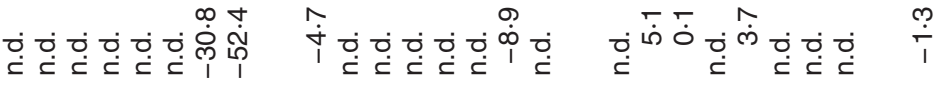

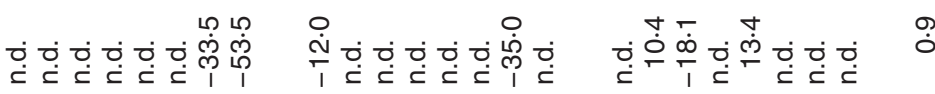

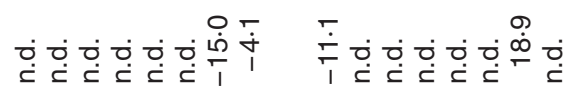

赵

$\stackrel{+}{\dot{4}}$

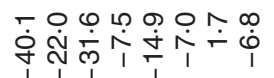

N 0 L

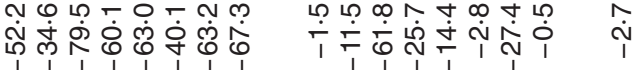

옹

$0 \infty$ m

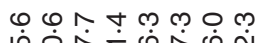

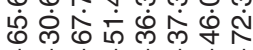

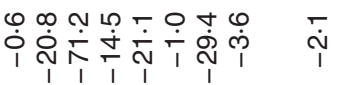

வ

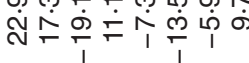

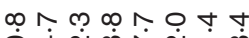

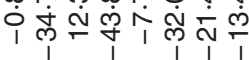

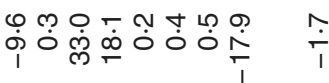

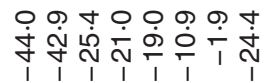

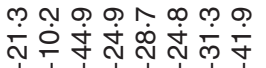

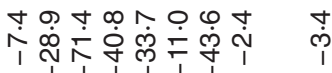

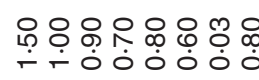

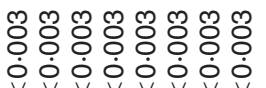

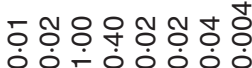

O̊
$\dot{0}$
$\dot{Q}$

|

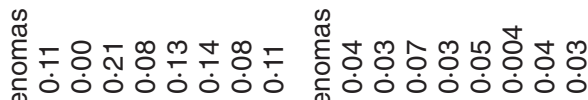

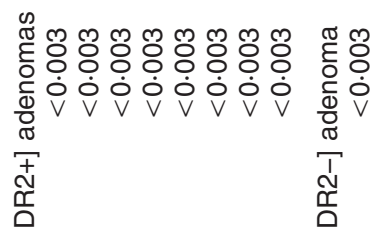

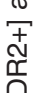

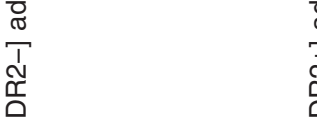

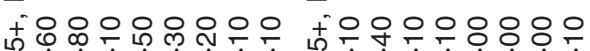

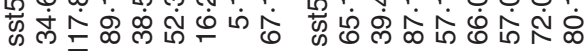

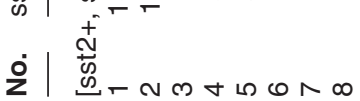

壹

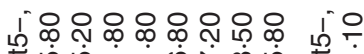

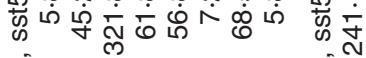

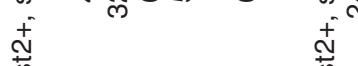

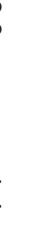


A

$[\mathrm{sst} 2+, \mathrm{sst} 5+, \mathrm{DR} 2+]$ adenomas

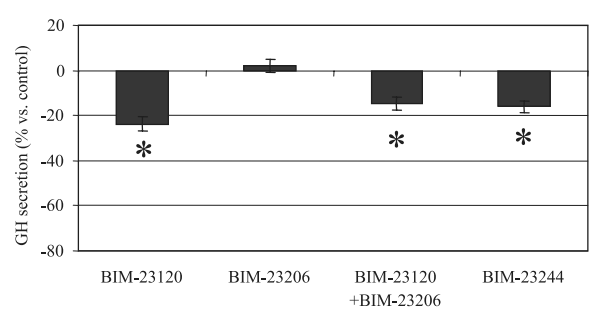

B

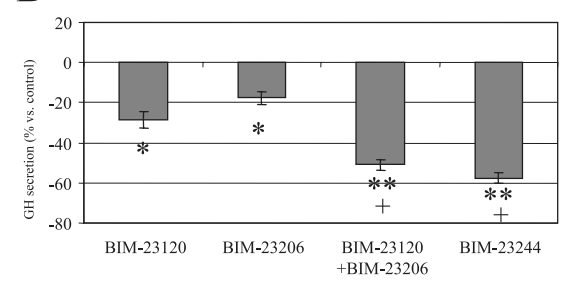

C

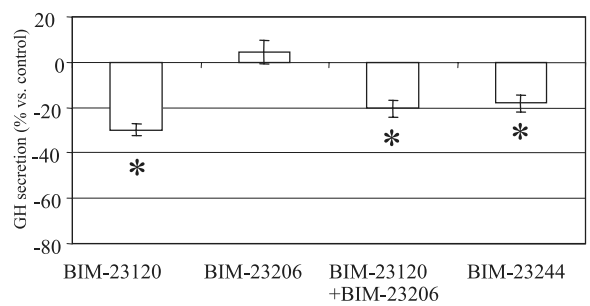

Figure 1 Effects of BIM-23120, BIM-23206 and BIM-23244 on GH secretion in pituitary primary cultures. Pituitary primary cultures were treated with each SRIF analog, alone or in combination, at $10^{-8} \mathrm{M}$ for $6 \mathrm{~h}$ and then GH concentration was assessed in the conditioned medium from eight replicates for each adenoma. GH secretion inhibition in primary cultures from

(A) eight somatotroph [sst2+, sst5+, DR2+] adenomas,

(B) eight somatotroph [sst2+, sst5+, DR2+] adenomas and

(C) eight somatotroph [sst2+, sst5-, DR2+] adenomas. Results are expressed as means \pm S.E. for $\mathrm{GH}$ suppression (\%) in treated cells with reference to untreated control cells. ${ }^{\star} P<0.05$ and ${ }^{* *} P<0.01$ versus untreated control cells; $+P<0.05$ versus cells treated with BIM-23120 or BIM-23206.

\section{Effects of selective SRIF analogs on PRL secretion}

Of the 25 pituitary primary cultures, eight secreted measurable amounts of PRL in the culture medium (mixed GH-/PRL-secreting pituitary adenomas; see Table 1). In order to determine whether the effects of sst-selective agonists on PRL secretion are influenced by DR2 expression, PRL levels were measured in conditioned media from the eight mixed GH-/PRLsecreting pituitary adenomas treated for $6 \mathrm{~h}$ with $10 \mathrm{M}^{-8}$ sst-selective agonists.

As shown in Fig. 2A and Table 3, we found that in the two [sst2+, sst5+, DR2+] adenomas treatment with the sst2-selective agonist (BIM-23120) did not influence PRL secretion, which was significantly inhibited
A $[\mathrm{sst} 2+, \mathrm{sst} 5+, \mathrm{DR} 2+]$ adenomas

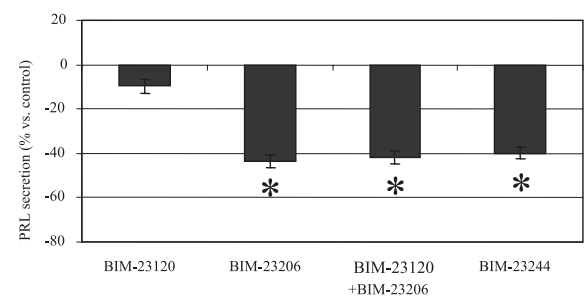

B [sst2+, sst5+, DR2-] adenomas

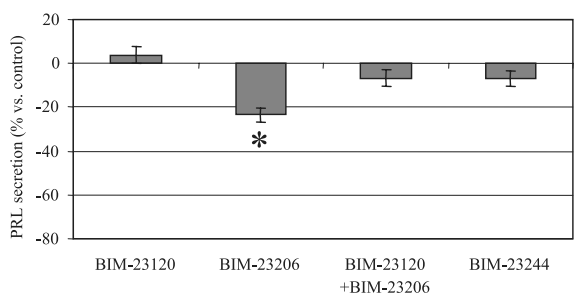

C $[$ sst2+, sstR5-, DR2+] adenomas

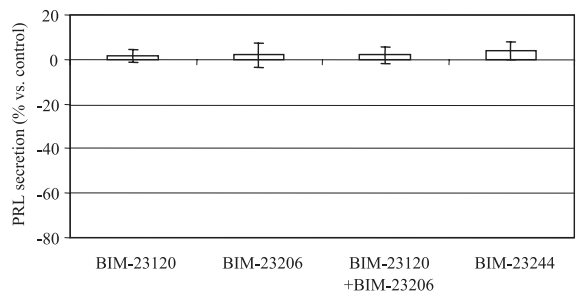

Figure 2 Effects of BIM-23120, BIM-23206 and BIM-23244 on PRL secretion in pituitary primary cultures. Pituitary primary cultures from mixed GH-/PRL-secreting pituitary adenomas were treated with each SRIF analog, alone or in combination, at $10^{-8} \mathrm{M}$ for $6 \mathrm{~h}$ and then PRL secretion was assessed in the conditioned medium from eight replicates for each adenoma. PRL secretion inhibition in primary cultures from (A) two mixed GH-/PRL-secreting [sst2+, sst5+, DR2+] adenomas, (B) two GH-/PRL-secreting [sst2+, sst5+, DR2-] adenomas and (C) three GH-/PRL-secreting [sst2+, sst5-, DR2+] adenomas. Results are expressed as means \pm S.E. for PRL suppression (\%) in treated cells with reference to untreated control cells. ${ }^{*} P<0.05$ versus untreated control cells.

$(P<0.01)$ by treatment with the sst5-selective agonist (BIM-23206), with the combination of the sst2-selective agonist and the sst5-selective agonist (BIM-23120+ BIM-23206) and with the sst2/sst5 dual agonist (BIM-23244) on average by $40-44 \%$. No additive effect was apparent for BIM-23120+BIM-23206 co-treatment, or for BIM-23244.

As shown in Fig. 2B and Table 3, in the two [sst2+, sst5+, DR2 - ] adenomas only treatment with BIM23206 was effective in reducing PRL secretion (on average $-23.5 \% ; P<0 \cdot 05)$. Moreover, treatment with BIM-23206 achieved a greater inhibition $(P<0 \cdot 05)$ in PRL secretion in $[\mathrm{sst} 2+$, sst5+, DR2+] adenomas as compared with $[$ sst2+, sst5+, DR2 -$]$ adenomas. 
Furthermore, as shown in Fig. 2C and Table 3, none of the selective sst agonists had any effect on PRL secretion in the three [sst2+, sst5 -, DR2+] adenomas. PRL secretion by the [sst2+, sst5 - , DR2 - ] adenoma (no. 25) was not modified by treatment with any selective sst agonist.

Moreover, the inhibitory effects of BIM-23206 correlated directly with sst5 and DR2 expression $\left(r^{2}=0.65\right.$ and 0.52 , respectively; $\left.P<0 \cdot 05\right)$.

\section{Discussion}

The demonstration of sst expression in human pituitary adenomas, even if highly heterogeneous (Nielsen et al. 1998), has provided several pharmacological tools for controlling hormonal hypersecretion by treatment with SRIF analogs (Hofland and Lamberts 2001). Moreover, DR expression has been documented extensively in vivo and in vitro in somatotroph adenomas with direct therapeutic implications in acromegalic patients (Koga et al. 1987, Ferone et al. 2001, Stefaneanu et al. 2001). Indeed, it has been shown that up to $30 \%$ of these patients are responsive to DA agonists (Abs et al. 1998), whereas in some cases dopaminergic agents are not effective, suggesting that DRs are not expressed or are less active (Bevan et al. 1989), since the absence of DR2 gene mutations in pituitary tumors has been demonstrated extensively (Friedman et al. 1994).

Our data demonstrate that sst and DR expression pattern may influence the antisecretory in vitro effects of SRIF analogs interacting with sst2 and/or sst5 in GH-secreting pituitary adenomas. According to previously published evidence (Shimon et al. 1997, Nielsen et al. 1998, Jaquet et al. 2000), in this study we found that sst2 is the most frequently expressed SRIF receptor subtype in $\mathrm{GH}$-secreting adenomas. The crucial role for sst2 in the control of $\mathrm{GH}$ secretion is further substantiated by the demonstration that the sst2-selective agonist (BIM-23120) significantly inhibits GH secretion to the same extent in $[\mathrm{sst} 2+$, sst5+, DR2+] and [sst2+, sst5+, DR2 - ] adenomas, as well as in [sst2+, sst5 -, DR2+] tissues. Moreover, the extent of GH secretion inhibition induced by the sst2-selective analog in vitro correlates significantly with sst2 expression. In this series of adenomas, sst2 mRNA levels are much higher than sst5 mRNA levels, in contrast with previous studies showing a prevalent sst5 expression in $\mathrm{GH}$-secreting pituitary adenomas (Jaquet et al. 2000, Saveanu et al. 2001, Hofland et al. 2004). In our study we performed an absolute quantitation of sst mRNA molecules in each sample, avoiding the need for expression normalization against a housekeeping gene, which is questionable for real-time PCR purposes (Bustin 2000). Housekeepinggene expression was indeed explored in order to evaluate RT efficiency. Moreover, we considered a threshold of $3 \times 10^{3} \mathrm{mRNA}$ copies/ $\mu \mathrm{g}$ total RNA to discriminate between effective mRNA expression and transcripts due to illegitimate transcription, as shown previously (Bustin 2000). In our series 9 out of $25 \mathrm{GH}-$ secreting pituitary adenomas had sst 5 or DR2 expression level below the considered threshold and, on the basis of methodological considerations, were considered as not expressing sst5 and/or DR2. These findings differ from that reported by other authors, who showed sst5 and DR2 expression in all samples examined (Saveanu et al. 2001, 2002). These discrepancies might be due to methodological issues, related to normalization procedures followed by these authors.

sst 5 and DR2 expression does not seem to influence BIM-23120 effects, suggesting that sst2 activation induces inhibitory effects on GH secretion independently of the expression of these two receptors. On the other hand, the sst5-selective agonist, BIM-23206, significantly inhibited GH secretion in $[\mathrm{sst} 2+$, sst5+, DR2 - ] tissues, but not in [sst2+, sst5+, DR2+] adenomas, indicating that DR2 expression might characterize a group of adenomas that are resistant to treatment with sst5-selective agonists. This hypothesis is further strengthened by the finding that DR2 expression correlates inversely with the inhibitory effects of the sst5-selective agonist on GH secretion. Moreover, our data show a lack of correlation between sst5 expression levels and the inhibitory effect on GH secretion of the sst5-selective agonist. Therefore, it is not surprising to find that the latter is more effective in $[\mathrm{sst} 2+$, sst5+, DR2 - ] adenomas, where sst5 is 3-fold less expressed than in $[\mathrm{sst} 2+, \mathrm{sst} 5+, \mathrm{DR} 2+]$ adenomas. Moreover, the lack of efficacy of the sst5-selective agonist in [sst2+, sst5-, DR2+] adenomas was in keeping with the absence of sst5 expression.

Treatment with the combination of sst2- and sst5-selective agonists (BIM-23120+BIM23206) obtained an additive effect in reducing GH secretion in [sst2+, sst5+, DR2 - ] adenomas, but not in [sst2+, sst5+, DR2+], supporting the hypothesis that DR2 expression might characterize a subgroup of adenomas which are less responsive to sst5-selective agonists, and further indicating a possible negative interaction between sst 5 and DR2 in the control of GH secretion. The lack of any additive effect of BIM-23120 and BIM-23206 on [sst2+, sst5 -, DR2+] adenomas was in keeping with the absence of sst5 expression. Treatment with the dual sst2/sst5 agonist (BIM-23244) obtained similar results, in line with previously reported evidence showing that the bi-selective analog can achieve greater GH suppression than sst2-preferential drugs (Saveanu et al. 2001).

In accordance with previous studies (Jaquet et al. 1999, Hofland et al. 2004) we found that sst5 activation is important for PRL secretion control, since the sst5-selective agonist (BIM-23206) significantly inhibited PRL secretion in both [sst2+, sst5+, DR2+] and [sst2+, 
sst5+, DR2 - ] mixed GH/PRL pituitary adenomas. Moreover, sst 5 expression directly correlated with the inhibitory effects of BIM-23206 on PRL secretion. In keeping with this evidence, the sst5-selective agonist was more effective in [sst2+, sst5+, DR2+] adenomas, where sst5 mRNA expression is significantly greater than in [sst2+, sst5+, DR2 - ]. These results might also indicate a possible positive interaction between sst5 and DR2 in controlling PRL secretion, contrary of that observed for GH. This hypothesis is strengthened further by the finding that DR2 expression correlates directly with the inhibitory effects of the sst5-selective agonist on PRL secretion. Moreover, the lack of efficacy of the sst5selective agonist in [sst2+, sst5 -, DR2+] adenomas was in keeping with the absence of sst5 expression. On the other hand, the sst2-selective agonist failed to affect PRL secretion in each group, suggesting that sst2, at least in this subset of adenomas, does not contribute significantly to PRL secretion control, as also shown previously in other experimental settings (Jaquet et al. 2000). This hypothesis is further supported by the lack of any additive effect of the co-treatment with BIM23120+ BIM-23206 or with the bi-agonist BIM-23244 on PRL secretion. Our results are in keeping with previous evidence showing that the dual sst2/sst5 agonist, BIM-23244, and a sst5-selective agonist, BIM-23268, suppress PRL secretion in GH-/PRL-secreting pituitary adenomas with similar potency (Saveanu et al. 2001).

Our findings indicate that, in adenomas lacking DR2 expression, sst2 and sst5 agonists have an additive effect on GH secretion inhibition, which is not evident when DR2 is expressed. Therefore, our data indicate a negative interplay between sst 5 and DR2 as far as GH secretion is concerned. On the other hand, inhibition of PRL secretion by the sst5-selective agonist is not enhanced by co-treatment with the sst2-selective agonist. Moreover, in DR2-expressing adenomas the sst5selective agonist is nearly 2-fold more potent in inhibiting PRL secretion, suggesting a positive interplay between sst5 and DR2.

It has been shown recently that in vitro sst 5 and DR2 associate on the plasma membrane and interact as functional oligomers (Rocheville et al. 2000b). Furthermore, sst5, existing in the basal state as a monomer upon activation by its ligand, forms sst 5 oligomers and also heterodimerizes with sstl (Rocheville et al. 2000a). Moreover, it has been shown that a hybrid molecule, BIM-23A387, with binding affinity for both sst2 and DR2, displays an enhanced potency in reducing GH secretion by pituitary adenomas (Saveanu et al. 2002). It is therefore possible that ssts and DRs assemble on the cell surface as oligomers and that the activation of a single receptor might have different effects depending on the components of the multi-receptor. Furthermore, as also suggested by our results, the activation of the same receptor complex might have different effects on secretory activities (Lamberts et al. 2002). Moreover, our results suggest that DR2 expression characterizes a group of adenomas that are less likely to respond to clinically available SRIF analogs in terms of GH secretion inhibition in vitro. Therefore, drugs interacting also with DR2 might achieve better results in the control of secretion and growth of pituitary adenomas, as demonstrated by Saveanu et al. (2002).

In conclusion, our results show that sst and DR expression pattern influence the effects of SRIF analogs on human GH-secreting pituitary adenomas, supporting the hypothesis of an interaction between these receptors. Further research is needed to fully elucidate the complex interplay between GPGRs and the consequent biological effects, to identify suitable therapies controlling hormonal secretion of pituitary tumors.

\section{Funding}

This work was supported by grants from the Italian Ministry of University and Scientific and Technological Research (University of Ferrara, 60\%-2003 and MIUR 2003069821-001), Fondazione Cassa di Risparmio di Ferrara and Associazione Ferrarese dell' Ipertensione Arteriosa. We thank Ipsen Italia for its support to this work. The authors declare that there is no conflict of interest that would prejudice the impartiality of this work.

\section{References}

Abs R, Verhelst J, Maiter D, Van Acker K, Nobels F, Coolens JL, Mahler C \& Beckers A 1998 Cabergoline in the treatment of acromegaly: a study in 64 patients. Fournal of Clinical Endocrinology E Metabolism 83 374-378.

Bevan JS, Burke CW, Esiri MM, Adams CB, Ballabio M, Nissim M \& Faglia G 1989 Studies of two thyrotropin-secreting pituitary adenomas: evidence for dopamine receptor deficiency. Clinical Endocrinology 31 59-70.

Bustin SA 2000 Absolute quantification of mRNA using real-time reverse transcription polymerase chain reaction assays. Fournal of Molecular Endocrinology 25 169-193.

Chelly J, Concordet JP, Kaplan JC \& Kahn A 1989 Illegitimate transcription: transcription of any gene in any cell type. PNAS 86 2617-2621.

Danila D, Sleiman Haidar JN, Zhang X, Katznelson L, Culler MD \& Klibanski A 2001 Somatostatin receptor specific analogs: effects on cell proliferation and growth hormone secretion in human somatotroph tumors. Fournal of Clinical Endocrinology $\&$ Metabolism 86 2976-2981

Ferone D, Pivonello R, Lastoria S, Faggiano A, Del Basso de Caro ML, Cappabianca P, Lombardi G \& Colao A 2001 In vivo and in vitro effects of octreotide, quinagolide and cabergoline in four hyperprolactinaemic acromegalics: correlation with somatostatin and dopamine D2 receptor scintigraphy. Clinical Endocrinology $\mathbf{5 4}$ 469-477.

Friedman E, Adams EF, Hoog A, Gejman PV, Carson E, Larsson C, De Marco L, Werner S, Fahlbusch R \& Nordenskjold M 1994 Normal structural dopamine type 2 receptor gene in prolactin-secreting and other pituitary tumors. Fournal of Clinical Endocrinology \& Metabolism 78 568-574. 
Hofland LJ \& Lamberts SW 2001 Somatostatin receptor subtype expression in human tumors. Annals of Oncology 12 S31-S36.

Hofland LJ, van der Hoek J, van Koetsveld PM, de Herder WW, Waaijers M, Sprij-Mooij D, Bruns C, Weckbecker G, Feelders R, van der Lely AJ, Beckers A \& Lamberts SW 2004 The novel somatostatin analog SOM230 is a potent inhibitor of hormone release by growth hormone-and prolactin-secreting pituitary adenomas in vitro. Foumal of Clinical Endocrinology $\mathcal{E}^{2}$ Metabolism 89 $1577-1585$

Jaffe CA \& Barkan AL 1992 Treatment of acromegaly with dopamine agonists. Endocrinology \& Metabolism Clinics in North America 21 713-735.

Jaquet P, Ouafik L, Saveanu A, Gunz G, Fina F, Dufour H, Culler MD, Moreau JP \& Enjalbert A 1999 Quantitative and functional expression of somatostatin receptor subtypes in human prolactinomas. Fournal of Clinical Endocrinology \& Metabolism 84 3268-3276.

Jaquet P, Saveanu A, Gunz G, Fina F, Zamora AJ, Grino M, Guller MD, Moreau JP, Enjalbert A \& Ouafik LH 2000 Human somatostatin receptor subtypes in acromegaly: distinct patterns of messenger ribonucleic acid expression and hormone suppression identify different tumoral phenotypes. Fournal of Clinical Endocrinology \& Metabolism 85 781-792.

Koga M, Nakao H, Arao M, Sato B, Norma K, Morimoto Y, Kishimoto S, Mori S \& Uozumi T 1987 Demonstration of specific dopamine receptors on human pituitary adenomas. Acta Endocrinology 114 595-602.

Korbonits M, Bustin SA, Kojima M, Jordan S, Adams EF, Lowe DG, Kangawa K \& Grossman AB 2001 The expression of the growth hormone secretagogue receptor ligand ghrelin in normal and abnormal human pituitary and other neuroendocrine tumors. Fournal of Clinical Endocrinology \& Metabolism 86 881-887.

Lamberts SW, de Herder WW \& Hofland L 2002 Somatostatin analogs in the diagnosis and treatment of cancer. Trends in Endocrinological Metabolism 13 451-457.

Melmed S, Jackson I, Kleinenberg D \& Klibanski A 1998 Current treatment guidelines fro acromegaly. Fournal of Clinical Endocrinology \& Metabolism 83 2646-2652.

Melmed S, Casanueva FF, Cavagnini F, Chanson P, Frohman L, Grossman A, Ho K, Kleinberg D, Lamberts S, Laws E et al. 2002 Guidelines for acromegaly management. Fournal of Clinical Endocrinology \& Metabolism $874054-4058$.

Nielsen S, Mellemkjaer S, Rasmussen LM, Ledet T, Astrup J, Weeke J \& Jorgensen JO 1998 Gene transcription of receptors for growth hormone-releasing peptide and somatostatin in human pituitary adenomas. Fournal of Clinical Endocrinology \& Metabolism 83 2997-3000.

Patel YC 1999 Somatostatin and its receptor family. Frontiers of Neuroendocrinology 20 157-198.

Ren SG, Kim S, Taylor J, Dong J, Moreau JP, Culler MD \& Melmed S 2003 Suppression of rat and human growth hormone and prolactin secretion by a novel somatostatin/dopaminergic chimeric ligand. Fournal of Clinical Endocrinology \& Metabolism 88 5414-5421.
Rocheville M, Lange DG, Kumar U, Patel SG, Patel RC \& Patel YC $2000 a$ Receptors for dopamine and somatostatin: formation of hetero-oligomers with enhanced functional activity. Science $\mathbf{2 8 8}$ 154-157.

Rocheville M, Lange DG, Kumar U, Sasi R, Patel RG \& Patel YC $2000 b$ Subtypes of the somatostatin receptor assemble as functional homo-and heterodimers. Fournal of Biological Chemistry 275 7862-7869.

Saveanu A, Gunz G, Dufour H, Caron P, Fina F, Ouafik L, Culler MD, Moreau JP, Enjalbert A \& Jaquet P 2001 Bim-23244, a somatostatin receptor subtype 2-and 5-selective analog with enhanced efficacy in suppressing growth hormone $(\mathrm{GH})$ from octreotide-resistant human GH-secreting adenomas. Fournal of Clinical Endocrinology \& Metabolism 86 140-145.

Saveanu A, Lavaque ED, Gunz G, Barlier A, Kim S, Taylor JE, Culler MD, Enjalbert A \& Jaquet P 2002 Demonstration of enhanced potency of a chimeric somatostatin-dopamine molecule, BIM23A387, in suppressing growth hormone and prolactin secretion from human pituitary somatotroph adenoma cells. Fournal of Clinical Endocrinology \& Metabolism 87 5545-5552.

Shimon I, Taylor JE, Dong JZ, Bitonte RA, Kim S, Morgan B, Coy DH, Culler MD \& Melmed S 1997 Somatostatin receptor subtype specificity in human fetal pituitary cultures. Differential role of SST2 and SST5 for growth hormone, thyroid stimulating hormone, and prolactin regulation. Fournal of Clinical Investigation 99 789-798.

Stefaneanu L, Kovacs K, Horvath E, Buchfelder M, Fahlbusch R \& Lancranjan L 2001 Dopamine D2 receptor gene expression in human adenohypophysial adenomas. Endocrine 14 329-336.

Vance ML, Evans WS \& Thorner MO 1984 Drugs five years later: bromocriptine. Annals of Internal Medicine 100 78-91.

Wood DF, Johnston JM \& Johnston DG 1991 Dopamine, the dopamine D2 receptor and pituitary tumors. Clinical Endocrinology 35 455-466.

Zatelli MC, Tagliati F, Taylor JE, Rossi R, Culler MD \& degli Uberti EC 2001 Somatostatin receptor subtypes 2 and 5 differentially affect proliferation in vitro of the human medullary thyroid carcinoma cell line TT. Fournal of Clinical Endocrinology \& Metabolism 86 2161-2169.

Zatelli MC, Piccin D, Tagliati F, Ambrosio MR, Margutti A, Padovani R, Scanarini M, Culler MD \& degli Uberti EC 2003 Somatostatin receptor subtype 1 selective activation in human growth hormone-and prolactin-secreting pituitary adenomas: effects on cell viability, growth hormone and prolactin secretion. Fournal of Clinical Endocrinology \& Metabolism 88 2797-2802.

Zatelli MC, Piccin D, Tagliati F, Bottoni A, Luchin A \& degli Uberti EC 2005 SHP-1 restrains cell proliferation in human medullary thyroid carcinoma. Endocrinology $1462692-2698$.

Received 14 July 2005

Accepted 27 July 2005

Made available online as an Accepted Preprint on 24 August 2005 